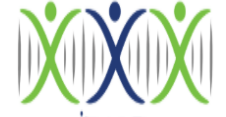

iRASD

Volume 9, Number 3, 2021, Pages 482-494

SCIENCES (PJHSS)

Journal Homepage:

https://journals.internationalrasd.org/index.php/pjhss

\title{
Exploring the Perceptions of Undergraduate Psychology students towards Online Engagement in English for Specific Purpose Classes
}

\author{
Muhammad Hassan Abbasi ${ }^{1}$, Mariam Aftab ${ }^{2}$ \\ ${ }^{1}$ Senior Lecturer, H\&SS Bahria University Karachi Campus \\ Email: mhassan.abbasi@outlook.com \\ ${ }^{2}$ Coordinator, Usman Public School \& Visiting Faculty NEDUET Karachi University \\ Email: mariamaftab89@gmail.com
}

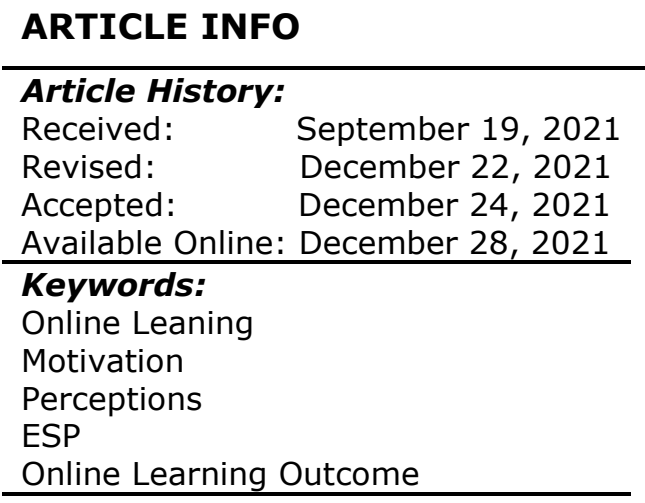

\section{ABSTRACT}

In today's global world, online teaching and learning have become an important part of the education system. In Pakistan, Covid-19 has revolutionized the teaching methodology from traditional face-to-face classes to online classes due to the closure of educational institutes. Despite various efforts made by HEC, universities, and teachers, yet students face problems in online classes. Therefore, the present study aims to explore the perceptions of undergraduate psychology students towards online engagement in ESP classes using self-determination theory (SDT). For this purpose, a qualitative study has been utilized and data has been collected in two stages using sociolinguistic profiles and interviews. The data was collected using a purposive sampling size from 35 psychology students enrolled in ESP online course. The data from the sociolinguistic profile has been analyzed using frequency analysis and interview data has been codified for thematic analysis. The findings suggest that both extrinsic and intrinsic motivation play an equal part in online learning. Besides this, the learners reported that learning can happen within online classes, depending on the teacher's methodology and strategies in online classes. The results are effective for higher education institutes in determining the level of motivation and perceptions respondents have while taking ESP courses online, which can be made interactive by developing outcome-based courses with the integration of technology to fit the needs of modern education in the post-Covid-19 world.

(c) 2021 The Authors, Published by iRASD. This is an Open Access Article under the Creative Common Attribution Non-Commercial 4.0

Corresponding Author's Email: mhassan.abbasi@outlook.com

\section{Introduction}

The novel coronavirus has brought with it many economic, social, health and education problems. This enabled individuals to live in the new normal by practicing social distance, selfquarantine and virtual interaction (Sigala, 2020). WHO (2020) declared the first case of coronavirus in December in Wuhan, China. However, the first case in Pakistan was reported in February. WHO (2020) recommended strong actions to be taken in order to save the public from the effects of coronavirus. In this scenario, the government of Pakistan decided to impose a lockdown in the whole country. Subsequently, all the business centers, public offices and educational institutes were closed. Importantly, Higher Education Commission and Ministry of education and vocational training in coordination with provincial education ministers decided to suspend physical academic activities and started online education to save the future of students (Quraishi, Asif, Sheeraz and Amer, 2020).

Higher Education Commission in Pakistan advised universities to develop a mechanism for online classes which was to be developed using a Learning Managements System (LMS). Quraishi, Asif, Sheeraz and Amer (2020) reported that online education had many administrative, management and academic challenges, but there are certain benefits as well 
such as convenience and flexibility (Mejia, 2020; Sisson \& Kwon, 2020). The academic challenges are more important as it facilitates the smooth flow of education and the quality of educational instruction in online classes. As every institute selected its own teaching portal like Blackboard, Google Classroom, Microsoft Teams, Zoom, and Massive Open Online Course MOOC. The teachers and students lack of knowledge about operating and taking classes online on these platforms due to accessibility issues reported to be the major obstacles in online education (Xu \& Jaggars, 2014). According to PTA (2020), there are 62 million broadband subscribers in Pakistan, yet many still do not have internet facility available most of the time due to frequent power cuts for long hours. In such circumstances, institutes and teachers have to rely on the available infrastructural resources to teach; especially English language teachers who were teaching language skills (speaking, listening, reading and writing) virtually for the first time. Consequently, motivation, attitudes and perceptions of students towards English language courses in online education is of significant importance. Therefore, this study attempts to fill the gap in the literature by examining the perceptions of undergraduate students towards online engagement.

Motivation is one of the most important components that affects the online teachinglearning process. (Firat, Kilinc, \& Yuzer, 2017). Motivation is defined as students' active involvement in interaction and desire to be part of an activity being carried in the classroom for successful learning outcome. (Artino \& Stephens, 2009; Goh \& Kim, 2020). Research studies have categorized motivation into two types: extrinsic and intrinsic. So in order to attain the particular objective, intrinsic and extrinsic motivation is essential. Meece \& Holt (1993), Moyo (2009) and Utvær \& Haugan (2016) defines extrinsic motivation as the one in which people are involved in different activities because of external reward (marks, grades, and punishment and are interested in how others perceive them. Whereas intrinsic motivation is the one in which people are engaged in different activities due to internal wishes and desires and apply different learning strategies for achieving a learning outcome (Ames \& Archer, 1988; Dweck \& Leggett, 1988) and engage in fun learning rather than rote learning (Ryan \& Deci, $2000,2017)$. Both of them have essential roles in achievement of different goals and aims. Moreover, English language classrooms in Pakistan focus on rote learning rather than skill based learning. Also, students from different disciplines have low-motivation for English courses as compare to their major discipline courses. In these circumstances, Covid-19 introduced a situation where learners because of social isolation in their homes were already facing mental health issues. Therefore, their personal motivation, connectivity with the learning material and engagement with peers and within groups is of significant importance in the context of psychology students (Chen \& Jang, 2010; Chiu \& Hew, 2018).

Chiu and Hew (2018) narrated that online resources and teaching activities ultimately enhance students' interest and facilities learning process. Holistically the performance of the learner gets improved. In this regards, motivation plays an important role especially in learning English for specific purposes because the course objective is to learn the skills to attain a language outcome in the future. As Cook (2008, p. 139) explained that "high motivation is one factor that causes successful learning; in reverse, successful learning causes high motivation".. Therefore, the choice of teaching material, content and activities of the lesson need to be appropriate. It should correspond to the motivations of the students.

Online language teaching introduced many challenges especially developing motivation among learners for learning English. It has become a challenging task as it affects the attitudes and perceptions of the learners towards online education. With this dramatic shift in the online classes, it is important to investigate the perceptions of psychology students towards online engagement in ESP course by analyzing their self-motivation, preference for student autonomous and feelings to connect with the learning material.. Therefore, this paper attempts to identify the psychological traits using a framework by closely examining the perceptions of students in online classes. As it attempted to provide some insights from the learners for the universities and HEC to improve the quality of education. Previously in the preCorona world students were forced to online learning, but by investigating their psychological perceptions, multiple learning opportunities can be provided in the post-COVID world. It includes synchronous, asynchronous, blended/hybrid learning modes. As students are the important stakeholders of the education sector, their perception towards online education is directly related to the success of online education. The objective of study is to explore the perceptions of undergraduate psychology students towards online engagement in the ESP 
classrooms. The research questions is: What are the perceptions of undergraduate psychology students towards online engagement in the ESP classroom?

\section{Literature Review}

Online education started even before the pandemic in most of the countries. However, in Pakistan it became the only medium of teaching in the post-Covid world. Jeffery, Oberlander, MacDonald and Bhatti (2016) conducted a study for the British council and reported that Pakistan lacks infrastructural assistance like the effective use of technology for successfully running the online education. Shah (2017) had a similar view that universities lack of infrastructural support and economic issues were the major hurdles in transforming traditional face-to-face classes to digital education. The first survey based study, exploring the perspectives of students, both undergraduate and graduate students was conducted by Adnan \& Anwar (2020). The results reported that $67.5 \%$ students narrated that online learning is very different from the traditional classes while $18.3 \%$ felt no major difference between online and physical classes because of the teaching practices. But $10.3 \%$ respondents elaborated that online learning is more encouraging and motivating than conventional classes. In another study, Abbasi, Ayoob, Malik and Memon (2020) explored the perceptions of medical students regarding distance learning during Covid-19 using the quantitative descriptive cross-sectional method. Data was collected using an online questionnaire to 382 ( 245 female and 137 male) participants. The findings showed that $77 \%$ of the respondents had negative perceptions about distance learning and students find online education less appealing than face-to-face sessions.

Drenan, Kennedy and Pisarki (2005) explored the attitudes of learners towards online education even before the world entered into the deadly pandemic. The study focused on two key attributes, students ease in terms of access, flexibility, and learning styles using a survey questionnaire and technology acceptance model. Data was collected from students enrolled in introduction to management course. The findings suggested that students' satisfaction is related in building positive perception on the effective use of technology and empowering independent learning. Similarly, Wei and Chou (2020) developed a structural model to determine the satisfaction and readiness of learners in online classes using a questionnaire. The data was collected from 356 students enrolled in Taiwan. The analysis showed that students' knowledge of computer skills and technology enabled them to actively participate in online classes. Also student's positive motivation and eagerness for learning had a direct relationship in shaping their perceptions towards online classes.

Previous studies have mainly focused on determining the advantages and disadvantages of online learning (Bolliger \& Halupa, 2018; Liaw \& Huang, 2013; Weidlich \& Bastiaens, 2018). As the focus is on students' attitudes towards technology which includes computer and internet. However, with the advent of easy access to social media platforms, blogs and websites, students' perceptions towards the use of technology are changing (Alzahrani \& O'Toole, 2017; Joyce \& Kirakowski, 2015; Wei \& Chou, 2019). Therefore, webbased resources and videos can be used as instructional material and incorporated to teach four language skills. This would ultimately enhance the motivation of learners in online classes. Liaw (2007) explored the perceptions of college students towards online learning and concluded that students' responses have four dimensions. These four dimension had e-learning as its central dimension which promotes self-independent learning with the effective learning environment, totally virtual interaction and teacher as the role model for e-learning. In the same way Wei and Chu (2019) applied Self-determination theory (Deci \& Ryan, 1985) as a framework to investigate the perceptions and motivation of learners. As Bertea (2009) and Morris (2009) concluded that learners performance improved with a positive experience of technology. Duggan (2001) explored the educational use of the internet and their behavior towards it. The findings suggested that if the students' perceptions are positive, they are likely to choose a course which applied learning on the digital forum. Additionally, Yang and Lin (2010) identified that if learners have positive perceptions they are interested in interacting and participating in digital forums, discussions and posting their assignment and write-up virtually. Therefore, a positive perception in using the internet for education purpose can shape the minds of learners. Consequently, Paechter and Maier (2010) examined perceptions of students that constitute a favorable environment for learning from 2196 students in Australian universities. The results supported that good online learning material and 
monitoring one's progress throughout the semester promote positive perceptions among learners.

Past research has been done to examine the factor of students' motivation and perceptions towards online classes and technology using survey based studies. As studies have relied on final grades and feedback at the end of the semester which mostly students fill out to achieve academic benefit from the students. Subsequently, this study focuses on continuous assessment and language development in identifying the effect of online education on the motivation of learners and their perceptions towards online engagement in English for a specific purpose course which focuses on the four skills of language. Therefore, this study aimed to explore perceptions of student's towards their performance and engagement in online ESP classes.

\section{Theoretical Framework}

As the present study aims to explore the effect of online classes on the perceptions of learners in online ESP classes. Therefore, it uses the self-determination theory (SDT) developed by Deci \& Ryan (1985) as a framework to examine the perceptions of students regarding the engagement in learning the four skills of language. As self-determination theory denotes that student's engagement is activated and energized by motivation and positive attitude. It tells us about the three parameters that humans require in a learning process: needs, motivation and well-being of learners within the social context. (See Figure 1).This theory explains that the three factors autonomy, competence and relatedness make the learners to act or not to act in a certain way. If the learner's needs are fulfilled than the learners have high motivation and psychological well-being, but if the needs are not satisfied than the learner experience isolation and low-motivation to be engaged in a learning process. Therefore, classrooms and teaching methodology where these three needs are activated promote positive learning environment and high motivation (Reeve, 2013).

\section{Figure 1: Self Determination Theory Framework}

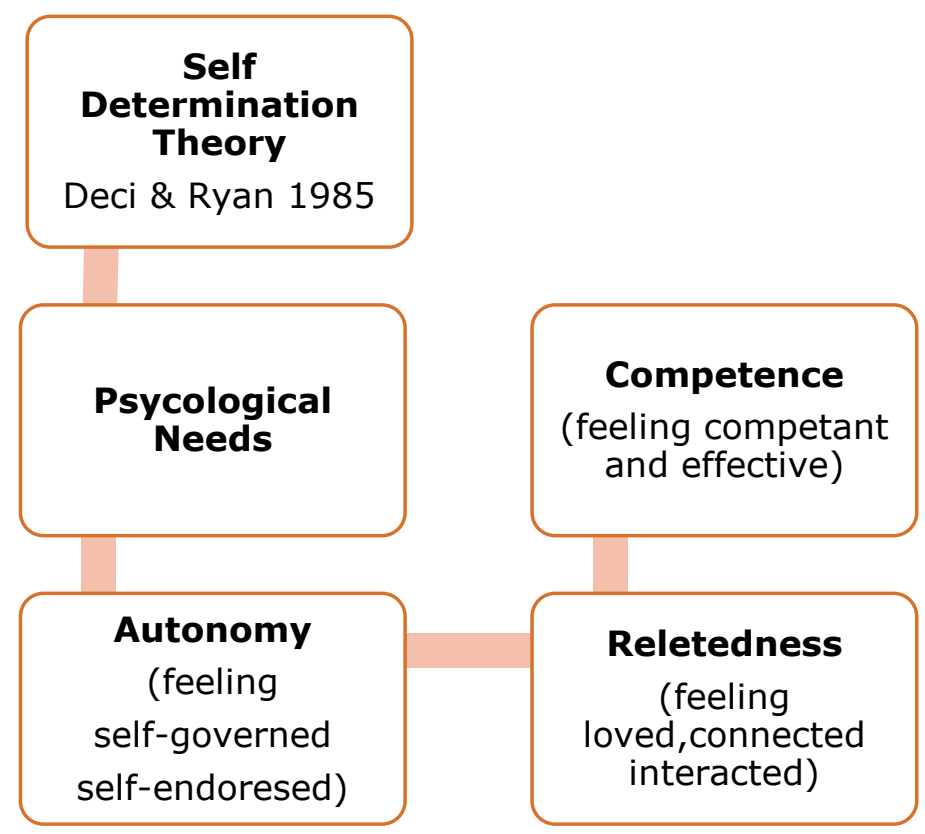

Chiu (2021) and Wei and Chu (2019) used the same framework to explore the motivation and perceptions of students towards online learning. Hence, the present study used the SDT framework to explore the needs, competence and relatedness of learners in motivating them to be engaged in online ESP classes. The SDT framework is mostly used in face-to-face classes. However, Chiu (2021) suggested that in the present scenario studies that all the future studies must focus on online and distance learning and their effect on the motivation and engagement of learners during the online classroom. Consequently, the present study uses SDT to identify the perceptions of students towards the online engagement in ESP classes, which was previously primarily identified using survey based studies. In this study, SDT has been utilized for exploring learners' autonomy, personal motivation during online ESP classes and their relatedness i.e connectivity with the learning material Thus, this 
study provides an in-depth first-hand respondent's viewpoints towards the online engagement. As this is relatively a new area of exploration in Pakistan. This study contributes in the underexplored area of ESP in online classes and SDT by discussing in detail the effect of motivation and perceptions of learners.

\section{Methodology \\ 4.1 Research Design}

The study aims to identify the perceptions of students towards online engagement in ESP classes. This study utilizes a qualitative approach to know about the skills of learners and engagement practices during online classes focusing on three factors in SDT theory. As this study focuses on one classroom, therefore it utilizes case study design.

\subsection{Population}

The population of this study includes undergraduate psychology students of a public sector university. The population includes both the male and female students and the reason for selecting the institute is its diverse population. The target population is undergraduate psychology students enrolled in the second semester studying English II course. This course is designed to specifically meet the needs and improve the skills of learners, it includes four skills, business communication and writing, grammatical knowledge required to deal in professional life in the future. These students have been selected because English II is the compulsory subject offered at the university in learning and developing competence in the four skills of language for professional life.

\subsubsection{Sampling Technique, Sample Size \& Instrument}

As the study focuses on a single classroom, therefore all the students in the classroom have been given an opportunity to participate using purposive sampling. The sample consist of 35 participants. All the respondents were asked to fill the sociolinguistic profile which collects demographic profile, perceptions about online classes in general and language skills. The sociolinguistic profile was piloted and validated by external reviewers (one international and two local). After careful analysis of the questionnaire, ten respondents were interviewed after formal written consent using the semi-structured interview to know about the perceptions of students regarding online engagement. Semi-structured interviews were utilized to know about the feelings, opinions and views of the learners during online classes and engagement strategies and techniques used by the teacher. This tool was used as it provides in-depth analysis. Interviews were taken online on Google Meet because of Covid-19 as per university instructions, following the SOPs issued by HEC. The interviews were scheduled in consultation with the interviewee and interview schedule and consent form was shared through email and WhatsApp contact number. Upon acknowledgement and prior consent, interview data was recorded, transcribed and the data was coded, categorized and themes were generated. The interviews with an individual student lasted for 35-40 minutes and overall it took 06 to 07 hours to collect data from the ten participants. The interviews were taken in English, video recorded and transcribed in English, the grammatical errors were edited for analysis. During the interview, ethics and interview protocol were followed as learner's convenience, time and setting was given priority and the respondent was given the choice whether to open the camera or not in the virtual recorded interview on Google Meet.

\subsection{Data Analysis}

Data from the sociolinguistic profile was utilized for frequency analysis as the major focus was on identifying the perceptions of learners. While data from interviews was used for thematic analysis using Saldana's model of thematic analysis. All the participants of the study were given a unique code so that their identity was not disclosed. Also, the respondents were given the assurance that this data will be used for academic purposes only. For reliability and validity of the data, the data was shared with an ELT expert for inter-coder reliability, and most of the themes matched with the researcher's analysis. Also, the analyzed data was shared with the respondents for member checking to see whether the data had been accurately represented and coded. 


\section{Findings}

Sociolinguistic profile inquired information about the demographic details, perceptions about online classes and English skills of the learners whether they were able to improve or acquire the skill or not. The analysis of the profile is given below.

\subsection{Online Education facilitates the learning process}

The analysis of the questionnaire in figure 2 shows that almost $55 \%$ disagreed that online education facilitates the learning process in general. Similarly, 35\% agreed that online education is better than physical one. While $10 \%$ showed neutral response.

\section{Figure 2: Online Classes}

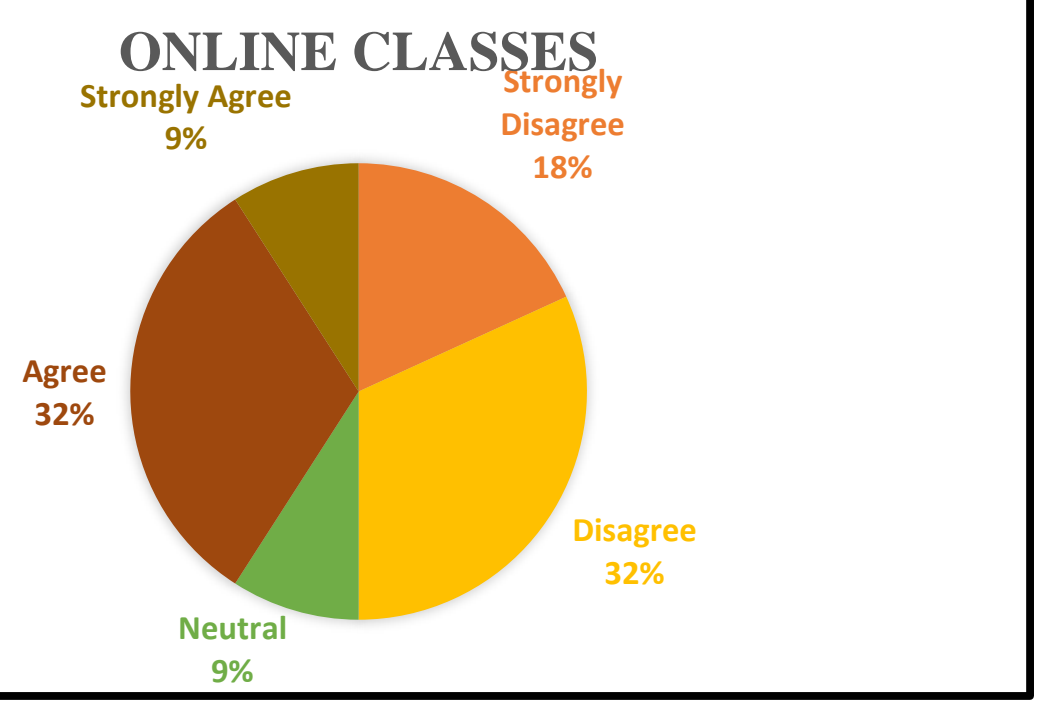

\subsection{Lecture Delivery, Digital Literacy, and Feedback in Online classes}

Table 01 below shows the frequency analysis of the different statements in the sociolinguistic profile that aim to identify the learner's response towards lecture delivery, feedback and a comparison between online and physical classes.

Table 1: Questionnaire Analysis

\begin{tabular}{|c|c|c|c|c|c|}
\hline Statements & $\begin{array}{l}\text { Strongly } \\
\text { Disagree }\end{array}$ & Disagree & Neutral & Agree & $\begin{array}{c}\text { Strongly } \\
\text { Agree }\end{array}$ \\
\hline $\begin{array}{l}\text { i. Easy to comprehend lecture } \\
\text { online classes }\end{array}$ & $23.4 \%$ & $22.7 \%$ & $24.5 \%$ & $22.3 \%$ & $7.2 \%$ \\
\hline $\begin{array}{l}\text { ii. Easy to understand } \\
\text { tasks/activities in online classes. }\end{array}$ & $23.4 \%$ & $25.2 \%$ & $21.6 \%$ & $22.7 \%$ & $7.2 \%$ \\
\hline $\begin{array}{l}\text { iii. Feel comfortable in } \\
\text { communicating in English in online } \\
\text { classes }\end{array}$ & $14.4 \%$ & & & $\%$ & $11.5 \%$ \\
\hline $\begin{array}{l}\text { iv. Online mode of instruction is } \\
\text { more interesting than traditional } \\
\text { classrooms. }\end{array}$ & $33.9 \%$ & $27.1 \%$ & $16.8 \%$ & $13.6 \%$ & $8.6 \%$ \\
\hline $\begin{array}{l}\text { v. Teacher's digital literacy is } \\
\text { important in online classes }\end{array}$ & $31.3 \%$ & $15.9 \%$ & $9.8 \%$ & $26.9 \%$ & $16.1 \%$ \\
\hline $\begin{array}{l}\text { vi. Feedback is required in online } \\
\text { classes }\end{array}$ & $3.3 \%$ & $5 \%$ & $30 \%$ & $45.1 \%$ & $16.6 \%$ \\
\hline $\begin{array}{l}\text { vii. It is easy to learn a language } \\
\text { in online classes }\end{array}$ & $30 \%$ & $30 \%$ & $10 \%$ & $4 \%$ & $26 \%$ \\
\hline $\begin{array}{l}\text { viii. I face many problems in } \\
\text { online classes. }\end{array}$ & $10 \%$ & $10 \%$ & $20 \%$ & $30 \%$ & $30 \%$ \\
\hline ix. I prefer online classes & $37 \%$ & $23 \%$ & $10 \%$ & $10 \%$ & $20 \%$ \\
\hline I prefer physical classes & $10 \%$ & $10 \%$ & $10 \%$ & $40 \%$ & $30 \%$ \\
\hline
\end{tabular}


As respondents while answering about lecture delivery show that $46.1 \%$ disagreed and $29.5 \%$ agreed that online lectures were easy to comprehend. Similarly, $48.6 \%$ disagreed and $29.9 \%$ agreed that it was easy for them to understand the task/activities in online classes. Consequently $24.5 \%$ disagreed and $49.1 \%$ agreed and $11 \%$ agreed that they felt comfortable in communicating in English in online classes.

However, $52 \%$ of the respondents agreed that it was easy for them to get the material only and $20 \%$ disagreed with them. While, $60 \%$ disagreed that online mode of instruction was more than better physical classes. In the same way, $43 \%$ of the respondents claimed that the teacher's digital literacy was important in online classes while $57 \%$ disagreed with them. As feedback is an important component of teaching, and learning a language, therefore, almost $61 \%$ agreed that it was also required in online classes and $30 \%$ of the respondents remained neutral about it.

\subsection{Thematic Analysis}

The main objective of this study was to know about the perceptions of students about engagement in online classes. Hence, Semi-structured interviews provided an in-depth exploration about the ESL classes and a contrast with the other online classes being offered during the semester. Most of the students as reflected from the analysis of the sociolinguistic profile preferred physical classes as they believe real learning happens in the classroom. However, the respondents narrated a different view as thematically analyzed below in online ESL classes.

\section{$5.4 \quad$ Teacher Support}

Real learning happens when the teacher understands and tries to resolve the problems of learners. As in ESL classes, teacher's major focus has to be the different skills acquired during the courses. "English classes were different because we learnt everything step like speaking, reading and writing skills" (MLE01). While narrating about teacher effective use of technology and content delivery one of the respondents said "Teacher's lecture delivery in the online classes was interactive and supportive, as the teacher used a variety of activities" (MLE07). In the online classes' students' major concern as highlighted by Quraishi, Asif, Sheeraz and Amer (2020) has been network issues, speed and flexibility. But MLE34 responded that that "We were not afraid that because of getting disconnected or facing lowconnectivity we would be marked absent as in other classes; as the teacher assured that the lecture would be available in the Google classroom created immediately after the class and the students can listen to it. The teacher can view who watched the lecture" Another respondent shared the experience as "We use different non-verbal to mark our attendance like thumbs-up, smiling face and other emoji's. We were not afraid to be marked absent, as the teacher informed that Google meet generates an attendance sheet which clearly shows the time".

Similarly, respondents narrated that the teacher used a variety of platforms for learner's ease and as per instructions of the university management, "We took our ESL classes on different platforms Google Meet, Team, Zoom and even WhatsApp to become familiar with all the applications" In the same way another respondent said "We were more comfortable in using Google meet as it provided good voice and visual quality as compared to others"

In short, the respondents appreciated the efforts of the teacher and strategy for tackling the attendance and internet issue and the use of technology and all the applications. As one respondent said "Teacher's efforts and activities motivated us to take regular classes"; "Interactive and learner's voice was more important than merely a teacher speaking" and "English classes motivated us to speak, read and write as it appealed and encouraged creativity and critical thinking".

\subsection{Online ESL Teaching Methodology}

Another important and major concern within ESL classes has been with regard to instruction, material and content delivery. While responding to a question with regard to instruction in online ESL classes, the participant said that "teacher used simple instructions and slides. The slides were creative. The teacher effectively uses bitmojis, GIFs and emoji's in his lecture slides". Another participant responded that "I was surprised by the fact that how can the teacher use these tools as they are used frequently on social media only". In the same 
way another responded while commenting said "The teacher used formal, interactive and visuals that suits the learning content". While narrating about visuals, one respondent shared the experience that "visuals activate your knowledge system and take you back in the past like during the pre-writing lecture, he showed us different pictures and used them for writing prompts. We wrote our responses on a paper and then showed it on our screens". Hence the material and content was emotionally appealing which was designed to promote positive learning atmosphere

While talking about the resources and material, MLE032 said "beside, in-class online learning, the teacher promptly maintains the LMS portal and the lecture slides were available on the portal before the class. Therefore, as summarized in the words of a respondent, "teacher offered various sources links, videos and slides and allowed us to study anywhere and anytime. As another respondent said that "We did not have in-classes online activities but offline activities as well where we were require to share our thought and opinions like I remember in one of the speaking task our teacher asked us to record our opinions about opening your cameras". One another participant remarked I believe, in the speaking, voice note task the teacher was trying to explore the idea whether students are comfortable or not, and I believe he did not force us to open our cameras during online classes. However, he used to open his camera and sometimes create a bitmoji of his own in slides. The teacher also used a number of scavenger hunt games to build the confidence and engage in communicative activities. As narrated by a respondent that "the teacher would use a letter and ask us to find as many things beginning with that letter". Another participant remarked; "the teacher would sometime ask us to open our camera and show that item as well". In the same way one respondent said, the virtual gift activity was the best; it was later, I realized that the teacher used it to teach us grammar"

In short, the teacher used communicative method approach and planned different activities to meet the needs of learners. As in the words of a learner "the teacher used to give online lectures and recorded lectures as well'. Another respondent narrated "that the ideology behind recorded lecture was to watch it at our pace and internet availability". Though there were students who did not watch the videos" Similarly another respondent said "Even in the recorded lectures we used to have activities and writing tasks.

\subsection{Assessment and Feedback in Online ESL Classes}

The respondents shared that the teacher used a variety of activities and quizzes to assess during the semester. As the respondents said, "I really like Kahoot, we used to compete among ourselves and the teacher at the last used to congratulate the three winners" The teacher used different applications like Kahoot, Quiziz, and Poll everywhere to assess and practice content. In the same way, one respondent narrated that "the best part was that they were not marked and used for practice purposes" While remarking about assessment one respondent said that "these activities helped us to get good marks". Subsequently, to check the amount of learning in each class, one participant remarked that "the teacher used an exit ticket activity towards the end of the classes to check our understanding". "The best part was that the teacher right after the class asked which one was your favorite and least-favorite activity". And student remarked, "The next day we would see some change"

In the same way, dividing students into groups in online classes is difficult. However, the respondents give a contrastive view. As one participant said, "the letter writing task was interesting, as we were divided into groups and wrote the letters collectively and the teacher frequently joined each group to give feedback". Similarly, another participant said, "we had a online reading race, the teacher assigned a passage and asked us to write the questions and answers and then in the online classes we had a competition". In the same way, another participant said "peer-writing task was the best, because we learn about editing our work before the teacher points out our mistakes" In the same way, another respondent said that "we had a movie watching class as well and after that we were assigned a writing task in groups, where we recreated different characters and it was the best class of the semester"

With regard to the final assessment, the respondents narrated "the management made the assessment hectic as the major focus was to turn on our cameras and attempt the paper" Another responded said "the paper was easy, as were required to attempt it on paper and MS 
word". Similarly, another respondent said "giving the paper online was best because we can get the feedback from the teacher and understand our errors and mistakes in the paper"

\subsection{Student Oriented Classes}

As other online classes promote teacher-centered classes, ESL classes were unique, as we were engaged in variety of online and offline activities and the lecture-span was short as well. "The teacher used different confidence building measures to give us confidence and make us independence learners. As one respondent narrated that "teacher promoted studentcentered classes and gave everyone an equal opportunity to speak-up". Similarly, another participant said that "the teacher use different strategies to empower us". While commenting about the mode of classes, one respondent said that "the teacher usually used to begin the class with a "Google jam board writing activity" where all the students share their opinions". Similarly, another respondent said that "the teacher used different engagement activities like we used to discuss in groups and share with the teacher and then the teacher used to deliver the content to enhance our learning process" In short, the teacher gave the authority to "selflearn and practice the information by providing access to different sources and links for knowledge"

\subsection{Anxiety, Stress and Mental Health}

ESP classes focuses on real-learning. As a respondent said, "the teacher encouraged and facilitated learning by avoiding unnecessary stress and demands on student". Another respondent said "we used to have bonus-marks activities as well" In the same way while talking about interaction with the teacher one responded reported that "The teacher involved us in different games and activities". While narrating about some examples, the respondent narrated that "Speaking and writing tasks addressed real-life issues". In the same way another responded said "The teacher welcomed our thoughts through free-writing and read and give feedback on our experiences" and "We were allowed to be engaged in group-speaking activities". Consequently, while talking about the learning environment, one respondent said, "the teacher allowed to use English in a stress-free environment and most of the students were able to speak and be a confident speaker in the future" Similarly, "It was surprising to see that students who were usually shy in physical classes spoke as well". Overall, it can be summarized in the words of a participant that "The teacher addressed students' individual interest"

Similarly, a respondent while talking about mental health and stress during online classes said "the teacher used different easy to go application that did not require any training and promoted learning" Also, teacher motivation and positive approach towards learning is important as one respondent said, "it is the teacher who creates a vision and build future leaders" Also, one student remarked that "the teacher used a mixed variety of activities and focused on pair-work and group-work that reduced social isolation and kept us motivated.

Also, to keep students engaged the teacher used physical movement during online classes to address the challenges faced by kinesthetic learners. As remarked by one of the respondents "the teacher would appreciate by showing thumps-up when somebody complete a task". Consequently another respondent said, "The teacher used "a lot of energizers that require physical exercise and non-verbal cues". Hence, non-verbal communication plays an equal part in ESL classes.

Screen-timings also increases a number of health issues as well. The students while narrating their experience said "the teacher used off-screen activities as well". Another remarked perhaps for one day "we do not have to be virtual, rather off-screen task was assigned using a pen and paper. Similarly, "the best part was sharing it with the teacher and getting instant comment or feedback afterwards". In the same way, another remarked, "the teacher effectively used the offline tasks and engaged us to show us some creativity using graphic organizers".

\section{$5.9 \quad$ Teacher Training}

Most of the learners believe that teacher-training is an important factor in online classes. As a respondent said "English classes made us realize that online learning can be engaging and interactive". In the same way another respondent said, "It was because our English teacher was self-proficient in using the different tools that he was able to use them 
effectively with us". Also, the teacher's support and positive approach is essential, as one respondent said the teacher considered learner's home environment in mind while designing and drafting different activities. In the same way another participant said, "The teacher used different confidence building measure, it was because of the support and motivation that we were able to give recorded presentations by switching on our camera and final exam live. Therefore, teacher training before online classes, motivation and interactive teaching methodology are highly important in online classes.

Figure 3: Modified Self-Determination Framework

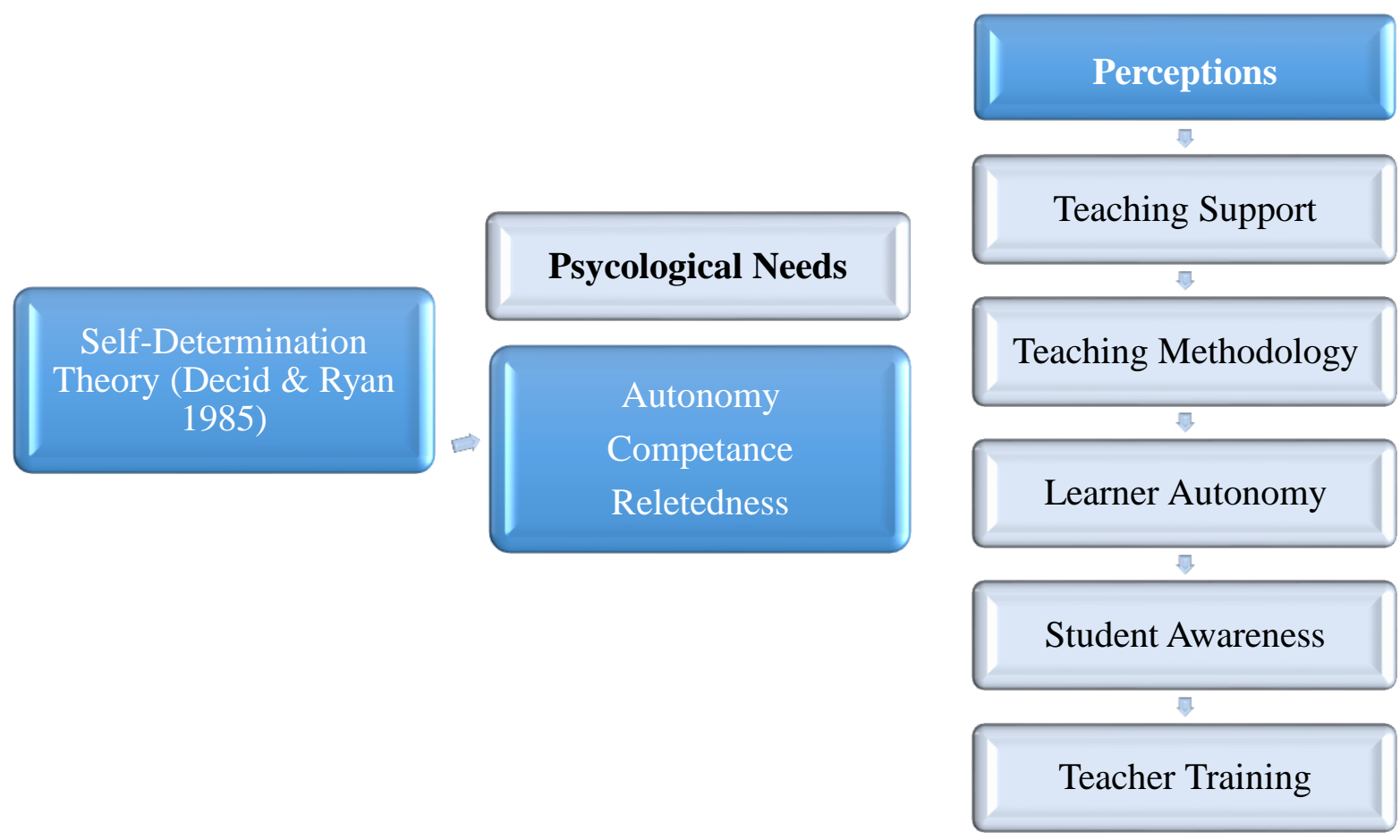

Hence in online classes teachers, and learner's positive approach towards learning, teaching methodology, approach, material, lesson plans, interaction, student interest, teacher support and the continuous assessment result in an effective learning environment. Hence, modified self-determination theory framework (Deci \& Ryan; 1985) considering the perceptions of learners can be utilized in future studies.

\section{Conclusion and Discussion}

This study shows that the learners had negative perceptions about online education in general as reflected through the analysis of the sociolinguistic profile. Contrastively, the learners had positive perceptions about online engagement in ESL classes where the teacher's methodology, support, autonomy kept them motivated in online classes. The analysis shows that an individual teacher used the digital technology and applications to teach language skills efficiently to learners. In the same way other studies can be conducted. Despite, having a negative attitude towards online classes; one ESL online class changed the perceptions and reshaped the definition of engagement in online classes in their minds.

Most of the studies conducted focused solely on impact and preference of students towards online education. (Adnan \& Anwar, 2020; Jeffery, Oberlander, MacDonald and Bhatti, 2016; Shah, 2016). But this study explores the real life experience and feelings of undergraduate students while taking online sessions. Also, mostly medical and engineering field has been explored more which require practical lab classes (Abbasi, Ayoob, Malik and Memon (2020). This study focuses on English for specific purposes which intakes the instruction for teaching and learning four skills of language that requires practical work as well.

Online learning has become the new-normal for educational institutes as accessibility and flexibility of learning from their home with feedback and quick assessment has a positive impact on the students. As the number of students enrolled in online courses over two semesters of pre-Covid world has rapidly increased. Therefore, the teacher may focus on professional training, digital methodology and using multiple activities that brings learners to 
real-life learning. This methodology and activities can be adopted by other course teachers to address the specific needs of their learner. For readers, some suggestions are given to adopt the best possible method for online classes along with the names of some online tools. Online teaching has changed the traditional role of teachers and now $21^{\text {st }}$ century teacher has to be a counselor, learning facilitator, assessor, curriculum evaluator, and teaching learning material organizer, supervisor and creator.

As highlighted in this qualitative case study that an individual teacher can create an impact in the online ESL classes. Therefore, the same approach can be adopted by other teachers in online classes. In this regard, HEC has already started Online Teaching Module for Higher education teachers. This study suggests that a three dimensional approach must be adopted by teachers using different activities, games and applications for online classes, namely synchronous, asynchronous and Look-away from screen teaching (See Figure 4 for best practices).Also, the teacher should revise the lesson plans into the following units: warmup: recalling back the information in the previous class; pre, while and post teaching activities which may involve using online tools like Padlet, wordwall, Jamboard (for speaking and writing), Quiziz, Kahoot and Poll everywhere (for assessment), YouTube, Tedtalks, ESL lounge and ESL lab (for listening), Google slides, canva and PowerPoint (for design instructions), screen casting, flip grid (for short videos and presentations) and other online tools according to the objective as shown in Figure 4. In this way, synchronous and asynchronous online teaching models can be followed. Synchronous teaching and learning happens while the teacher is delivering the lecture at a specified time using online LMS portal or applications while asynchronous happens anywhere and anytime depending upon one's schedule, where the teacher can share links and additional learning material online. In addition, the teacher can adopt off-screen method as well, reducing virtual screen time. This may be closer to real physical classes where through pen and paper many creative and critical thinking activities can be carried out.

Figure 4: An ESL Model to Online Engagement

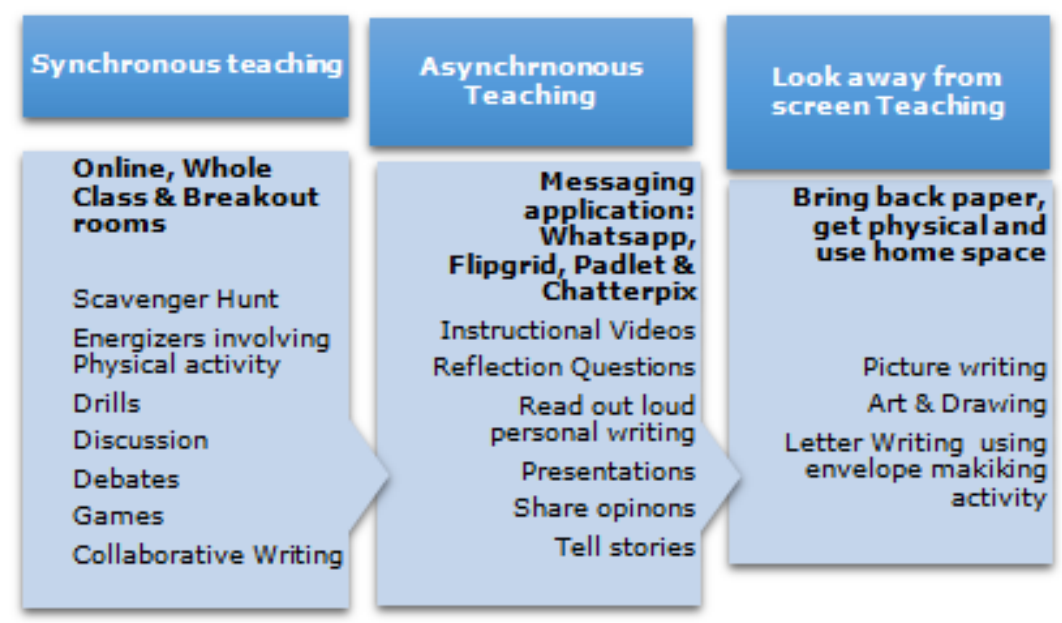

\section{References}

Abbasi, S., Ayoob, T., Malik, A., \& Memon, S. I. (2020). Perceptions of students regarding Elearning during Covid-19 at a private medical college. Pakistan Journal of Medical Sciences, 36 (COVID19 S4), 57-61. DOI: https://doi.org/10.12669/pjms.36.COVID19S4.2766

Adnan, M., \& Anwar, K. (2020). Online learning amid the COVID-19 pandemic: Students' perspectives. Journal of Pedagogical Sociology and Psychology, 2(1), 45-51.

Ames, C., \& Archer, J. (1988). Achievement goals in the classroom: Students' learning strategies and motivation processes. Journal of Educational Psychology, 80(3), 260267. https://doi.org/10.1037/0022-0663.80.3.260

Artino, A. R., \& Stephens, J. M. (2009). Academic motivation and self-regulation: A comparative analysis of undergraduate and graduate students learning online. Internet and Higher Education, 12(3-4), 146-151. https://doi.org/10. 1016/j.iheduc.2009.02.001

Ajzan, I. (1988). Attitudes, personality and behavior. Chicago: Dorsey Press. 
Alzahrani, M. G., \& O'Toole, J. M. (2017). The impact of Internet experience and attitude on student preference for blended learning. Journal of Curriculum and Teaching, 6(1), 6578. https://doi.org/ 10.5430/jct.v6n1p65

Amad, M., Ghani, M., \& Malik, A. M. (2020). Exploring the link between English and online mode of learning during Covid-19, Linguistics and Literature Review, 6(2), 109-116.

Bertea, P. (2009, April 9-10). Measuring students' attitude towards e-learning: A case study. Proceedings of the 5th International Scientific Conference on eLearning and Software for Education. https://adlunap.ro/else_publications/papers/2009/979.1.Bertea.pdf

Bolliger, D. U., \& Halupa, C. (2018). Online student perceptions of engagement, transactional distance, and outcomes. Distance Education, 39(3), 299-316. https://doi.org/10.1080/01587919.2018.1476845

Cook, V. (2008). Second Language Learning and Language Teaching. UK: Hodder Education.

Chen, K.-C., \& Jang, S.-J. (2010). Motivation in online learning: Testing a model of selfdetermination theory. Computers in Human Behavior, 26(4), 741-752. https://doi.org/10.1016/j.chb.2010.01.011

Chiu, Thomas K. F. (2021): Applying the self-determination theory (SDT) to explain student engagement in online learning during the COVID-19 pandemic, Journal of Research on Technology in Education.

Chiu, T. K. F., \& Hew, T. K. F. (2018). Asynchronous online discussion forum in MOOCs: Does openness matter for peer learning and performance? Australasian Journal of Educational Technology, 34(4), 16-28. https://doi.org/10.14742/ajet.3240

Deci, E. L., \& Ryan, R. M. (1985). Intrinsic motivation and self-determination in human behavior. Plenum. https://doi.org/10.1007/978-1-4899-2271-7

Duggan, A., Hess, B., Morgan, D., Kim, S., \& Wilson, K. (2001). Measuring students' attitudes toward educational use of the Internet. Journal of Educational Computing Research, 25(3), 267-281.

Dweck, C. S., \& Leggett, E. L. (1988). A social-cognitive approach to motivation and personality. Psychological Review, 95(2), 256-273. https://doi.org/10.1037/0033295X.95.2.256

Firat, M., Kilinc, H., \& Yuzer, T. V. (2017). Level of intrinsic motivation of distance education students of e-learning environments. Journal of Computer-assisted Learning, 63-70.

Goh, E., \& Kim, H. J. (2020). Emotional intelligence as a predictor of academic performance in hospitality higher education. Journal of Hospitality \& Tourism Education, 1-7. https://doi.org/10.1080/10963758.2020.1791140

Jeffery, R., Oberlander, J., MacDonald, S., \& Bhatti, F. (2016). Digital Citizenship in Pakistan. British Council Pakistan. Retrieved from www.britishcouncil.pk

Joyce, M., \& Kirakowski, J. (2015). Measuring attitudes towards the Internet: The general Internet attitude scale. International Journal of Human-Computer Interaction, 31(8), 506-517.

Judy Drennan, Jessica Kennedy \& Anne Pisarski (2005) Factors Affecting Student Attitudes Toward Flexible Online Learning in Management Education. The Journal of Educational Research, 98(6), 331-338.

Liaw, S. S., \& Huang, H. M. (2013). Perceived satisfaction, perceived usefulness and interactive learning environments as predictors to self-regulation in e-learning environments. Computers \& Education, 60(1), 14-24. https://doi.org/10.1016/j.compedu.2012.07.015

Lucey, K. (2018). The effect of motivation on student persistence in online higher education: a phenomenological study of how adult learners experience motivation in a web-based distance learning environment. (Doctoral Dissertation). Available from ProQuest Dissertations and Theses Database. 10750789.

Meece, J. L., \& Holt, K. (1993). A pattern analysis of students' achievement goals. Journal of Educational Psychology, 85(4), 582-590. https://doi.org/10.1037/ 0022-0663.85.4.582

Mejia, C. (2020). Using voice thread as a discussion platform to enhance student engagement in a hospitality management online course. Journal of Hospitality, Leisure, Sport \& Tourism Education, 26, 1-11. https://doi.org/10.1016/j. jhlste.2019.100236

Morris, T. A. (2011) Exploring community college student perceptions of online learning International Journal of Instructional Technology and Distance Learning, 8(6), 31-44.

Moyo, D. (2009). Dead aid: Why aid is not working and how there is a better way for Africa (1st ed.). Farrar, Straus, and Giroux. https://doi.org/10.1080/17441690903369469 
Paechter, M., Maier, B., \& Macher, D. (2010). Students' expectations of, and experiences in elearning: Their relation to learning achievements and course satisfaction. Computers \& Education, 54(1), 222-229. https://doi.org/10.1016/j.compedu.2009.08.005

PTA (2020). Internet Users in Pakistan. Pakistan Telecommunication Authority. Retrieved from https: //www.pta.gov.pk/en/telecom-indicators.

Quraishi, N. H., Asif, M., Sheeraz, M., \& Amer, K. (2020). Novel Coronavirus (COVID-19) and its impact on Education at Tertiary Level: Challenges and Solutions for Pakistani Universities, Journal of Education \& Social Sciences, 8 (2), 40-54.

Ryan, R. M., \& Deci, E. L. (2017). Self-determination theory: Basic psychological needs in motivation. The Guilford Press.

Ryan, R. M., \& Deci, E. L. (2000). Self-determination theory and the facilitation of intrinsic motivation, social development, and well-being. American Psychologist, 55(1), 68-78. https://doi.org/10.1037110003-066X.55.1.68

Sigala, M. (2020). Tourism and COVID-19: Impacts and implications for advancing and resetting industry and research. Journal of Business Research, 117. 312-321. https://doi.org/10.1016/j.jbusres.2020.06.015

Sisson, A. D., \& Kwon, J. (2020). Effectiveness of e-learning as seen by meeting planners. Journal of Hospitality \& Tourism Education, 1-14. https://doi.org/10.1080/10963758.2020. 1791138

Shah, B. H. (2017). Role of ICT in Distance Education in Pakistan. (Doctoral thesis) Islamic University of Bahawalpur. Retrieved from http://121.52.159.154:8080/jspui/bitstream/123456789/1712/1/Role\%20of\%20ICT\% 20in\%20Distance\%20Education\%20in\%20Pakistan.pdf

Utvær, B. K. S., \& Haugan, G. (2016). The academic motivation scale: Dimensionality, reliability, and construct validity among vocational students. Nordic Journal of Vocational Education and Training, 6(2), 17-45. https://doi.org/10. 3384/njvet.2242$458 \times .166217$

Weidlich, J., \& Bastiaens, T. J. (2018). Technology matters - The impact of transactional distance on satisfaction in online distance learning. The International Review of Research in Open and Distributed Learning, 19(3). https://doi.org/10.19173/irrodl.v19i3.3417

Wei, H.C., \& Chou, C. (2020) Online learning performance and satisfaction: do perceptions and readiness matter? Distance Education, 41(1). 48-69, DOI: $10.1080 / 01587919.2020 .1724768$

Wei, H. C., \& Chou, C. (2019). Relationships among college learners' online learning perceptions, behaviors, and achievements via the Self-Determination Theory approach [Paper presentation]. 2019 AERA Annual Meeting, Toronto, Canada.

WHO Reports (2020). Novel Coronavirus (Covid-19). World Health Organization. Retrieved from https://www.who.int/bulletin/online_first/COVID-19/en/

Xu, D., \& Jaggars, S. S. (2014). Performance gaps between online and face-to-face courses: Differences across types of students and academic subject areas. Journal of Higher Education, 85(5), 633-659. https://doi.org/10.1353/jhe. 2014.0028

Yang, Y., \& Lin, N. C. (2010). Internet perceptions, online participation and language learning in Moodle forums: A case study on nursing students in Taiwan. Procedia - Social and Behavioral Sciences, 2(2), 2647-2651. https://doi.org/10.1016/j.sbspro.2010.03.388 